\title{
Subtle hyperproinsulinaemia characterises the defective insulin secretory capacity in offspring of glutamic acid decarboxylase antibody-positive patients with latent autoimmune diabetes mellitus in adults
}

\author{
Ilkka Vauhkonen, Leo Niskanen, Mikael Knip ${ }^{1}$, Leena Moilanen Mykkänen, Steven Haffner ${ }^{2}$, Matti Uusitupa ${ }^{3}$
} and Markku Laakso

Department of Medicine and ${ }^{3}$ Department of Clinical Nutrition, Kuopio University Hospital and University of Kuopio, Finland, ${ }^{1}$ Hospital for Children and Adolescents, University of Helsinki, Helsinki, Finland and ${ }^{2}$ Department of Medicine/Division of Clinical Epidemiology, University of Texas, San Antonio, Texas, USA

(Correspondence should be addressed to I Vauhkonen, Department of Medicine, University of Kuopio, FIN-70210 Kuopio, Finland; Email: ilkka.vauhkonen@kuh.fi)

\begin{abstract}
Objective: We set out to assess whether hyperproinsulinaemia is an early finding in latent autoimmune diabetes in adults (LADA).

Research design and methods: We measured plasma proinsulin and C-peptide responses during a 2-h oral glucose tolerance test (OGTT) and in the hyperglycaemic clamp in 21 normoglycaemic offspring of LADA patients testing positive for glutamic acid decarboxylase antibodies (GADA) or islet cell antibodies (ICA), and in 17 healthy control subjects without a family history of diabetes.

Results: The study groups had comparable areas under the curves of blood glucose, plasma proinsulin, C-peptide and proinsulin/C-peptide in the OGTT. However, the offspring of LADA patients had higher proinsulin/C-peptide in the hyperglycaemic clamp $(P<0.01$ versus the control group). The offspring of GADA-positive LADA patients $(n=9)$ had higher proinsulin and proinsulin/C-peptide than did the control group in the OGTT $(P<0.05$ for both comparisons) and in the hyperglycaemic clamp $(P<0.001$ and $P<0.05$ respectively). They also had higher proinsulin than the offspring of ICApositive LADA patients $(n=12)(P<0.001)$ in the hyperglycaemic clamp. The offspring of ICA-positive LADA patients did not clearly show hyperproinsulinaemia during the tests, but they had lower maximal glucose-stimulated insulin secretory capacity than the control group $(P<0.05)$ and the offspring of GADA-positive LADA patients $(P<0.05)$ in the hyperglycaemic clamp.

Conclusions: These results suggested that insulin secretion in the offspring of GADA-positive LADA patients is characterised by subtle defects in the processing of insulin precursors. Furthermore, various proinsulin responses among the offspring of LADA patients with different autoimmune markers provided further evidence that LADA is a heterogeneous disorder.
\end{abstract}

European Journal of Endocrinology 153 265-273

\section{Introduction}

Latent autoimmune diabetes mellitus in adults (LADA) is a common disorder accounting for $10-15 \%$ of diabetes diagnosed in adulthood (1-6). LADA has genetic and metabolic features characteristic of type 1 diabetes (7). A recent study showed that LADA comprises a heterogeneous population of diabetic patients ranging from an aggressive form of $\beta$-cell autoimmunity to a more slowly progressing form with features of type 1 diabetes (8). We have previously shown in the offspring of LADA patients that impaired insulin secretion in LADA is familial (9). Interestingly, in that study impaired insulin secretory capacity was associated with parental history of islet cell antibodies (ICA) but not with glutamic acid decarboxylase antibodies (GADA). These findings support the concept of LADA being ultimately a heterogeneous disorder $(8,10)$.

High proinsulin concentrations and/or disproportionately increased proinsulin levels relative to insulin and/or C-peptide concentrations are commonly present at the diagnosis of type 1 diabetes (11-14) and are even seen in normoglycaemic first-degree relatives of affected patients (13-19). The significance of hyperproinsulinaemia in the pathogenesis of type 1 diabetes is, however, unclear but earlier studies have suggested 
that it may reflect an immunological $\beta$-cell insult as a secondary phenomenon $(15,19,20)$.

Although increased proinsulin concentrations are a characteristic feature of common type 2 diabetes (21), there is convincing evidence based on studies in firstdegree relatives of patients with this disease that hyperproinsulinaemia is not present before the deterioration of the glucose tolerance (22). Consequently, hyperproinsulinaemia in 'common' type 2 diabetes has been considered as a secondary phenomenon due to hyperglycaemia-induced $\beta$-cell stress (23).

No studies are available that have investigated whether hyperproinsulinaemia is an early finding in LADA. We therefore measured proinsulin concentrations in normoglycaemic offspring of patients with LADA. We also compared proinsulin responses in offspring of LADA patients in relation to GADA and ICA positivity to further assess the heterogeneity of LADA.

\section{Subjects and methods}

\section{Subjects}

The subjects for the present study were offspring of the patients who participated in a follow-up study with newly diagnosed type 2 diabetes $(24,25)$. The formation and representativeness of the study population have been described in detail earlier $(24,25)$. The probands for the present study were patients with type 2 diabetes who tested positive for ICA (3) or GADA (4) during the follow-up. Exclusion criteria for the selection of the offspring were: (a) diabetes mellitus in both parents or in the offspring, (b) drug treatment or any disease that could potentially modify carbohydrate metabolism, (c) pregnancy, (d) overt psychiatric disease and (e) age under 30 or over 55 years.

Offspring of the probands with GADA or ICA positivity (offspring of LADA patients) The formation of the study population for the present study has previously been described in detail (9). Briefly, there were 12 probands who tested positive for GADA at the baseline examination (4) and 15 probands who tested positive for ICA at the baseline and/or at the 5-year follow-up examination (3). Three probands were positive for both GADA and ICA and were excluded from this study. Originally, the offspring of LADA patients comprised 36 subjects (9). Proinsulin samples were available from 32 subjects. Only the normoglycaemic offspring of probands with GADA and the normoglycaemic offspring of probands with ICA positivity were included in the present study. Thus, the study groups for the present study comprised 21 normoglycaemic offspring of LADA patients. Nine of these subjects were offspring of five probands with GADA (offspring of GADA-positive LADA patients) and 12 subjects were offspring of four probands with ICA (offspring of ICA-positive LADA patients).
Control group The formation of the control group for the present study has been described in detail earlier (9). Briefly, the control subjects were offspring of individuals with repeatedly normal glucose tolerance according to the World Health Organisation criteria and GADA and ICA negativity (26). Furthermore, the control subjects had to fulfill the following inclusion criteria: (a) age from 30 to 55 years, (b) no diabetes, (c) first-degree relatives without a history of diabetes, (d) no drug treatment or any disease that could potentially modify carbohydrate metabolism and (e) no history of hypertension. Originally, the control group comprised 19 offspring (ten men and nine women) of 12 probands (9). Since plasma proinsulin samples were available from 17 subjects, the control group for the present study comprised 17 subjects.

\section{Study protocol}

The subjects were admitted for 2 days to the metabolic ward of the Department of Medicine, Kuopio University Hospital. On the first day a 2-h oral glucose tolerance test (OGTT) was performed after fasting for $12 \mathrm{~h}$ followed by a hyperglycaemic clamp. On the second day the hyperinsulinaemic euglycaemic glucose clamp was performed.

The protocol was approved by the Ethics Committee of the University of Kuopio. All subjects gave their informed consent.

\section{OGTT}

In a 2-h OGTT ( $75 \mathrm{~g}$ glucose) samples for blood glucose, plasma proinsulin and plasma $\mathrm{C}$-peptide were drawn at $0,30,60,90$ and $120 \mathrm{~min}$ to evaluate the degree of glucose tolerance and the $\beta$-cell response to an oral glucose load.

\section{Hyperglycaemic clamp}

At 120 min immediately after the 2-h OGTT the hyperglycaemic clamp was performed (27). Blood glucose was acutely increased to $20 \mathrm{mmol} / \mathrm{l}$ by a constant $20 \%$ glucose infusion and clamped at $20 \mathrm{mmol} / \mathrm{l}$ until $180 \mathrm{~min}$ by infusing $20 \%$ glucose at varying rates according to blood glucose measurements performed at 5-min intervals. At 150, 165 and 180 min samples were taken for the measurement of plasma C-peptide. In addition, at $180 \mathrm{~min}$ samples for the determination of plasma proinsulin were obtained.

\section{Intravenous glucose tolerance test (IVGTT)}

An IVGTT was performed to determine the first phase insulin secretory capacity. At $0800 \mathrm{~h}$ after a $12 \mathrm{~h}$ overnight fast, an intravenous catheter was placed in the antecubital vein for the infusion of glucose. Another canula for blood sampling was inserted into a wrist vein surrounded by a heated box $\left(40^{\circ} \mathrm{C}\right)$. After baseline 
blood collection, bolus of glucose $(300 \mathrm{mg} / \mathrm{kg}$ in a $50 \%$ solution) was given (within $30 \mathrm{~s}$ ) into the antecubital vein to acutely increase the blood glucose level. Samples for the measurement of blood glucose and plasma insulin were drawn at $-5,0,2,4,6,8$ and $10 \mathrm{~min}$.

\section{Euglycaemic clamp}

The degree of insulin resistance was evaluated with the euglycaemic hyperinsulinaemic clamp technique (27). A priming dose of insulin infusion (Actrapid (100 IU/ml); Novo Nordisk, Gentofte, Denmark) was administered during the initial $10 \mathrm{~min}$ to acutely raise plasma insulin to the desired level, where it was maintained by a continuous insulin infusion at a rate of $80 \mathrm{mU} / \mathrm{m}^{2}$ body surface area per min. Blood glucose was clamped at $5.0 \mathrm{mmol} / \mathrm{l}$ for the next $180 \mathrm{~min}$ by infusing 20\% glucose at varying rates according to blood glucose measurements performed at 5-min intervals (mean coefficient of variation of blood glucose was $<4 \%$ in both study groups and the control group). The data were calculated for each 20-min interval; the mean value for the period from 120 to $180 \mathrm{~min}$ was used to calculate the rates of whole body glucose uptake (WBGU).

\section{Assays and calculations}

Blood glucose concentrations in the fasting state, during the OGTT and during clamp studies were measured by the glucose oxidase method (Glucose \& Lactate Analyzer 2300 Stat Plus; Yellow Springs Instrument Co. Inc., Yellow Springs, OH, USA). For the determination of plasma immunoreactive insulin, plasma proinsulin and plasma C-peptide, blood was collected into EDTA tubes. After centrifugation, the plasma for the determination of immunoreactive insulin and Cpeptide was stored at $-20^{\circ} \mathrm{C}$ until the analysis. Plasma immunoreactive insulin and C-peptide were determined by RIA (Phadeseph Insulin RIA 100; Pharmacia Diagnostics AB, Uppsala, Sweden and a ${ }^{125}$ I RIA kit from Incstar Co., Stillwater, MN, USA respectively). Proinsulin concentrations were measured by a non-equilibrium RIA method (Human Proinsulin RIA kit; Linco, St Louis, MO, USA) (28). The polyclonal antibody used in this assay recognises a proinsulin-specific epitope formed by the intact A-chain-C-peptide junction. In this assay, the potency of human insulin and C-peptide is $<0.1 \%$ of that of proinsulin. Cross-reactivity with des 31,32 proinsulin is $95 \%$. The intra-assay coefficient of variation ranged from 6 to $21 \%$ using controls prepared at 5, 50 and $250 \mathrm{pmol} / \mathrm{l}(29)$.

The immunoreactive insulin area under the curve (AUC) in the $\mathrm{AUC}_{\text {(IVGTT) }}$ and the AUCs of blood glucose, plasma proinsulin, plasma $\mathrm{C}$-peptide and the plasma proinsulin to plasma $\mathrm{C}$-peptide ratio during the OGTT were calculated by the trapezoidal method. The maximal glucose-stimulated C-peptide secretion during the hyperglycaemic clamp was calculated as mean Cpeptide values measured at 150, 165 and $180 \mathrm{~min}$.

\section{Autoantibody tests}

The ICA analyses of the probands were performed in the Research Laboratory, Department of Pediatrics, University of Oulu, Oulu, Finland in 1990, while the ICA testing of the offspring was done in the same laboratory in 1997. The ICA assay was performed as previously described in detail (30). The results are expressed in Juvenile Diabetes Foundation units (JDF units) based on a standard curve. The cut-off value for ICA was 5 JDF units. The substrate used in 1997 gave a standard curve identical to that obtained with the substrate used in 1990. The laboratory has participated in the international workshops on the standardisation of the ICA assay with a sensitivity of $100 \%$ and a specificity of $98 \%$ in the most recent round.

GADA antibody tests for the probands were performed with a radio-immunoprecipitation assay (31) on serum taken at the baseline examination between 1979 and 1981. This method has been described previously in more detail (4). GADA antibody tests for the offspring in the present study were done by a radio-immunoprecipitation method employing ${ }^{35}$ S-labelled recombinant human GADA $_{65}$ produced by in vitro transcription/translation $(32,33)$. The E. coli clone with full-length human GADA $_{65}$ cDNA was a kind gift from Dr Allan E Karlsen and Catherine E Grubin, University of Washington (Seattle, WA, USA). The results are expressed as relative units (RU), RU = (sample c.p.m. - mean c.p.m. of three negative controls)/(c.p.m. of a positive internal reference serum - mean c.p.m. of three negative controls) $\times 100$. Antibody levels exceeding $5 \mathrm{RU}$ which represent the mean +3 s.D. of 296 Finnish healthy control subjects were considered positive. In the Combined Autoantibody Workshop (Orvieto, Italy 1995), the sensitivity of the assay was $75 \%$ and the specificity $99 \%$.

\section{Statistical analysis}

All calculations were performed with the SPSS for Windows program (SPSS Inc., Chicago, IL, USA). Data are shown as means \pm S.E.M. The differences between two groups were analysed by the Mann-Whitney non-parametric test or by the $\chi^{2}$ test when appropriate. In the subgroup analyses, the differences between the groups were tested by ANOVA for continuous variables and by Mantel-Haenszel's test for dichotomised variables. Only when the $P$ value was $<0.05$ were the two groups compared by Mann-Whitney non-parametric test or by the $\chi^{2}$ test. The analysis of covariance (ANCOVA) was used to adjust for confounding variables. 


\section{Results}

\section{Clinical and biochemical characteristics of the study groups}

The groups were comparable with respect to age, gender, body mass index and the rates of WBGU (Table 1). The offspring of LADA patients tended to have a lower $\mathrm{AUC}_{\text {(IVGTT) }}$ than the control group $(P=0.056)$. Otherwise, there were no differences in fasting blood glucose, fasting plasma proinsulin and $\mathrm{C}$-peptide concentrations between the study groups.

\section{OGTT}

There were no significant differences in the AUCs of blood glucose, plasma C-peptide, proinsulin and proinsulin to plasma C-peptide ratio during the OGTT between the control group and the offspring of LADA (Fig. 1).

\section{Hyperglycaemic clamp}

There were no significant differences in plasma C-peptide and proinsulin concentrations between the control group and the offspring of LADA patients during the hyperglycaemic clamp (Fig. 2). The offspring of LADA patients had, however, higher proinsulin to plasma C-peptide ratio than did the control group $(P=0.010)$.

\section{Subgroup analyses}

Clinical and biochemical characteristics Age, gender, body mass index and the rates of WBGU were comparable in the subgroups of the offspring of LADA patients (Table 1). The offspring of ICA-positive LADA patients had a lower $\mathrm{AUC}_{\text {(IVGTT) }}$ than the control group $(P=0.021)$ and the offspring of GADA-positive LADA patients $(P=0.006)$. Fasting blood glucose concentration did not differ significantly among the study groups (ANOVA; $P=0.11$ ). The offspring of GADApositive LADA patients had higher fasting plasma proinsulin and C-peptide concentrations than the control group $(P=0.034$ and $P=0.039$ respectively $)$ and the offspring of ICA-positive LADA patients $(P=0.007$ and $P<0.001$ respectively), even after adjustment for the rates of WBGU, fasting blood glucose or the family effect (ANCOVA; $P<0.05$ for all comparisons) (Table 1).

Among the offspring of ICA-positive LADA patients one subject had both ICA and GADA (66 JDF units and 123.5 RU respectively), among the offspring of GADApositive LADA patients one subject tested positive for GADA (10.0 RU), and among the control subjects one subject tested positive for GADA (13.1 RU).

OGTT There were no significant differences in blood glucose and plasma C-peptide AUCs during the OGTT

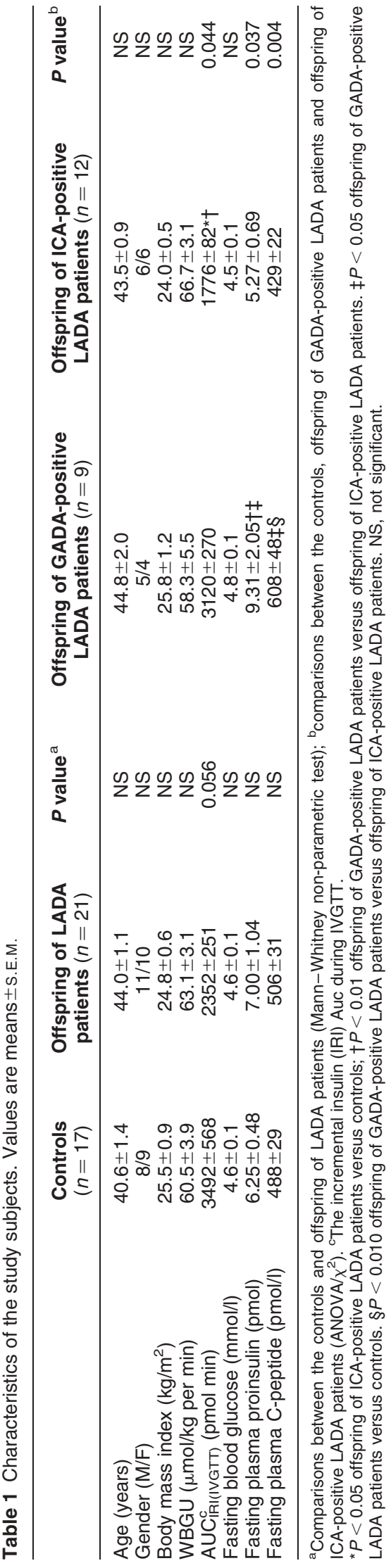

www.eje-online.org 

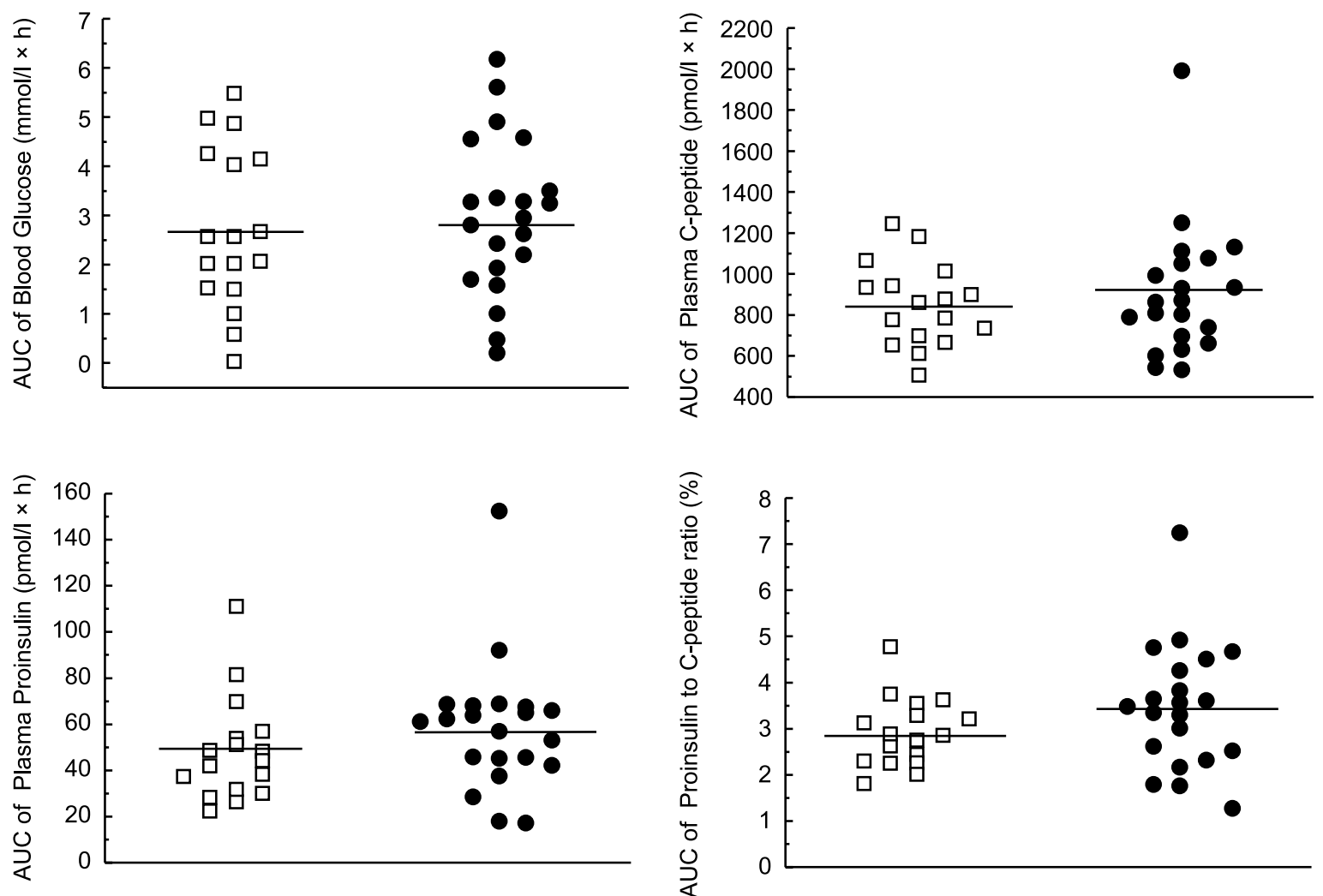

Figure 1 Individual AUCs of blood glucose, plasma C-peptide, plasma proinsulin concentrations and the proinsulin to C-peptide ratio during the OGTT. The control group $(\square)$ and the offspring of LADA patients $(\bullet)$ are shown. The solid line depicts the mean.

(Fig. 3). The offspring of GADA-positive LADA patients had, however, higher AUCs of plasma proinsulin and proinsulin to plasma C-peptide ratio than the control group $(P=0.025$ and $P=0.029$, respectively $)$. These differences persisted even after adjustment for WBGU and the family effect (ANCOVA; $P<0.05$ for all analyses).
Hyperglycaemic clamp The offspring of ICA-positive LADA patients had lower plasma C-peptide concentration than the offspring of GADA-positive LADA patients $(P=0.034)$ and the control group $(P=0.052)$ during the hyperglycaemic clamp (Fig. 4). On the other hand, the offspring of GADA-positive LADA patients had higher plasma proinsulin concentrations compared
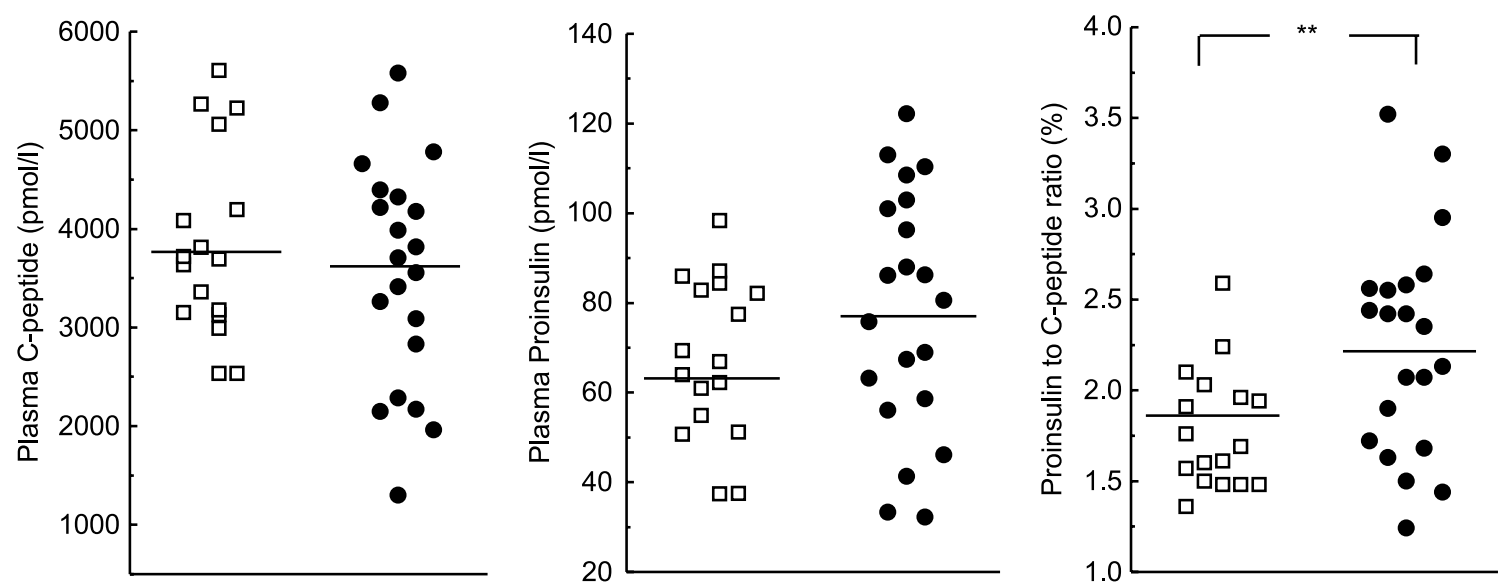

Figure 2 Individual maximal glucose-stimulated plasma C-peptide, plasma proinsulin concentrations and the plasma proinsulin to $\mathrm{C}$-peptide ratio in the hyperglycaemic clamp. ${ }^{\star} P=0.01$ between study groups. The control group ( $\square$ ) and the offspring of LADA patients $(\bullet)$ are shown. The solid line represents the mean. 

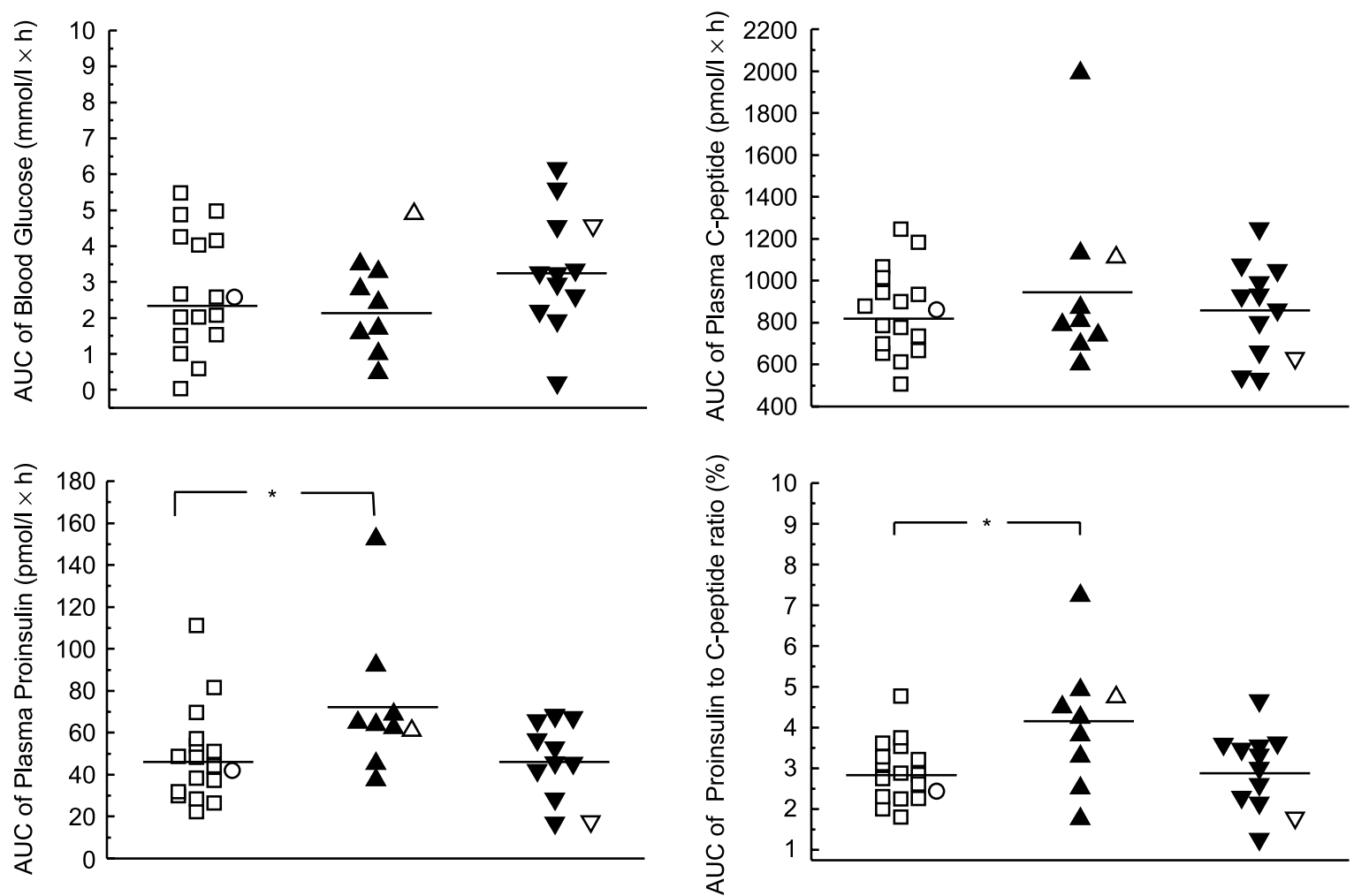

Figure 3 Individual AUCs of blood glucose, plasma C-peptide, plasma proinsulin concentrations and the proinsulin to C-peptide ratio in the two subgroups of offspring of LADA patients during the OGTT. The control group ( $\square$ ), the offspring of GADA-positive LADA patients $(\mathbf{\Lambda})$ and the offspring of ICA-positive LADA patients $(\mathbf{V})$ are shown. The control subject testing positive for GADA (O), the offspring of a GADA-positive LADA patient testing positive for GADA $(\triangle)$ and the offspring of an ICA-positive LADA patient testing positive for both GADA and ICA $(\nabla)$ are shown. ${ }^{\star} P<0.05$, offspring of GADA-positive LADA patients versus the control group. The solid line represents the mean.
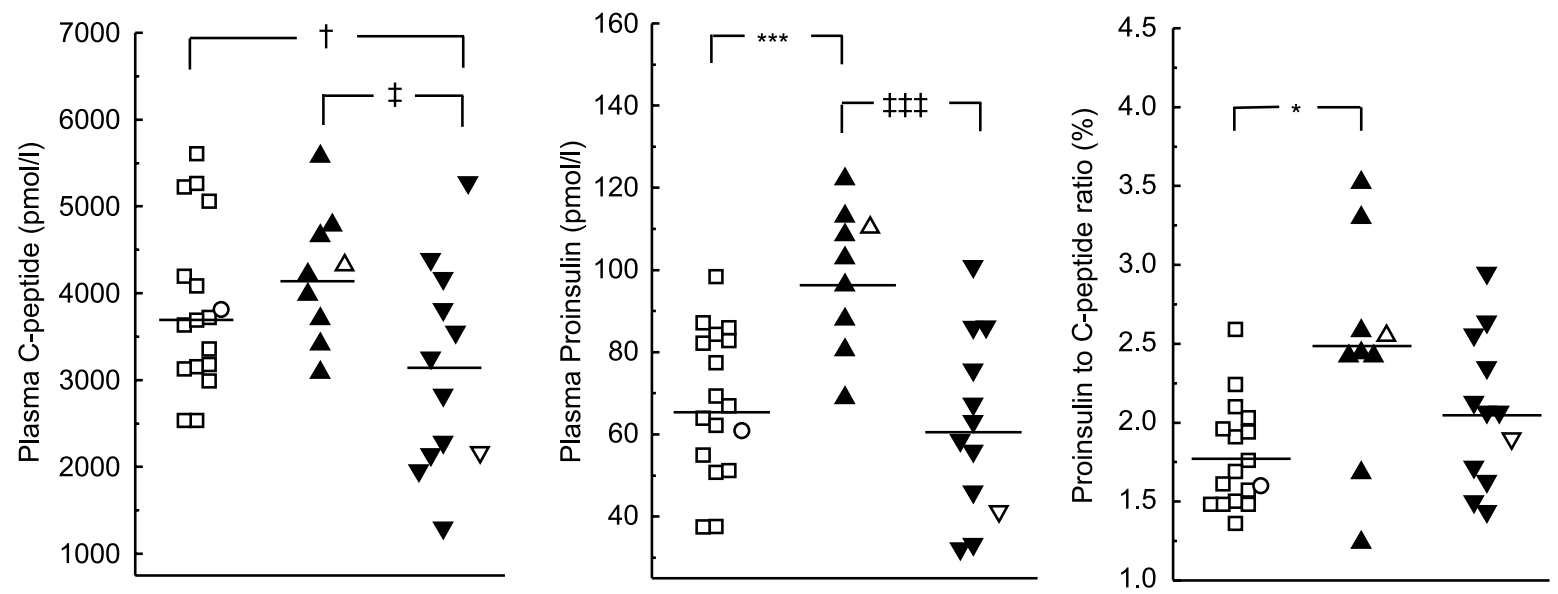

Figure 4 Individual maximal glucose stimulated plasma C-peptide, plasma proinsulin concentrations and the proinsulin to C-peptide ratio in the two subgroups of offspring of LADA patients in the hyperglycaemic clamp. The control group ( $\square$ ), the offspring of GADApositive LADA patients $(\mathbf{\Lambda})$ and the offspring of ICA-positive LADA patients $(\boldsymbol{\nabla})$ are shown. The control subject testing positive for GADA (O), the offspring of a GADA-positive LADA patient testing positive for GADA $(\triangle)$ and the offspring of an ICA-positive LADA patient testing positive for both GADA and ICA $(\nabla)$ are shown. ${ }^{\dagger} P<0.05$, offspring of ICA-positive LADA patients versus the control group, ${ }^{*} P<0.05$ and ${ }^{* * *} P<0.001$, offspring of GADA-positive LADA patients versus the control group and ${ }^{\ddagger} P<0.05$ and ${ }^{\ddagger \neq \pm} P<0.001$, offspring of GADA-positive LADA patients versus offspring of ICA-positive LADA patients. The solid line depicts the mean. 
with those of the offspring of ICA-positive LADA patients $(P<0.001)$ or the control group $(P<0.001)$. Furthermore, they had a higher proinsulin to plasma C-peptide ratio than the control group $(P=0.013)$.

\section{Discussion}

The novel finding of our study was that the normoglycaemic offspring of LADA patients, although having quite normal plasma proinsulin responses after an oral glucose load, showed disproportionately increased plasma proinsulin concentrations in the hyperglycaemic clamp. These results suggested that the impaired insulin secretory capacity in the offspring of LADA patients (9) is characterised by a subtle defect in the processing of insulin precursors, unlike in the offspring of patients with type 2 diabetes (34). On the other hand, although hyperproinsulinaemia was not so profound as described in first-degree relatives of patients with type 1 diabetes $(13-19)$ it supports the concept that LADA has metabolic features typical of classical type 1 diabetes. Moreover, hyperproinsulinaemia was observed only in the offspring of GADA-positive LADA patients, providing further evidence that LADA is a heterogeneous disorder $(8,10)$.

Hyperproinsulinaemia in subjects genetically predisposed to type 1 diabetes is considered to be secondary to a previous or ongoing attack on the $\beta$-cell $(15,19$, $20)$, although an inherent, non-autoimmune defect in the cleavage process of insulin precursors $(16,35,36)$ or decreased metabolic clearance of insulin $(37,38)$ cannot be excluded. Given that LADA comprises a subtype of type 1 diabetes, patients with LADA and their first-degree relatives should also have hyperproinsulinaemia. In the present study, the normoglycaemic offspring of LADA patients had disproportionately increased proinsulin concentrations when challenged with high blood glucose in the hyperglycaemic clamp. We have previously shown that the normoglycaemic offspring of autoantibody-negative patients with type 2 diabetes have normal proinsulin responses not only after an oral glucose load but also during the hyperglycaemic clamp, suggesting that hyperproinsulinaemia is not an early feature in common type 2 diabetes (34). Hyperproinsulinaemia in type 2 diabetes has been considered to develop secondary to $\beta$-cell stress induced by prolonged hyperglycaemia (23). Therefore, the present study suggested that the mechanisms of impaired insulin secretory capacity in LADA are closer to type 1 than type 2 diabetes.

Although the offspring of LADA patients did not show significant hyperproinsulinaemia at physiological glucose concentrations, proinsulin responses were heterogeneous between these subjects. We have previously reported that defects in insulin secretory capacity in these offspring of LADA patients were associated with a parental history of ICA positivity but not of GADA positivity (9). These results were somewhat unexpected since autoantibodies to GAD have been considered to be an even better predictor of progression to insulin dependency than are ICA in LADA patients $(39,40)$. In the present study, the offspring of GADA-positive LADA patients, although having quite normal insulin secretory capacity, showed increased plasma proinsulin levels both absolutely and relatively to plasma C-peptide after an oral glucose load and in the hyperglycaemic clamp. The offspring of ICA-positive LADA patients, on the other hand, had impaired first-phase and maximal glucose-stimulated insulin secretory capacity, but showed quite normal plasma proinsulin responses both in the OGTT and the hyperglycaemic clamp. These findings imply that GADA positivity in LADA reflects $\beta$-cell autoimmunity similar to classical type 1 diabetes whereas ICA positivity in LADA may be, at least partly, a secondary phenomenon.

Interestingly, the offspring of GADA-positive LADA patients had increased fasting C-peptide concentrations and somewhat higher fasting blood glucose concentration than the offspring of ICA-positive LADA patients, even after adjustment for their WBGU. This implies that these subjects have increased hepatic glucose output. It is possible that an autoimmune insult in the $\beta$-cells leads to disturbed pulsatile/oscillatory insulin secretion and subsequent impaired inhibition of hepatic glucose output. Consequently, the hyperproinsulinaemia in these subjects may be secondary to mild hyperglycaemia. Alternatively, it is possible that an autoimmune insult in the $\beta$ cells leads simultaneously to both a defective processing of proinsulin and disturbed pulsatile/oscillatory insulin secretion. Finally, a genetic defect in the cleavage process of insulin precursors without any autoimmune attack on the $\beta$-cells cannot be excluded.

Despite clearly reduced first-phase and maximal glucose-stimulated insulin secretory capacity, the normoglycaemic offspring of ICA-positive LADA patients had quite normal plasma C-peptide insulin and blood glucose responses after an oral glucose load. It is therefore possible that their impaired glucose-stimulated insulin secretion is compensated by an increased incretin effect. The impaired glucose-stimulated insulin secretory capacity in these subjects may therefore reflect a reduced quantitative or functional $\beta$-cell mass due to a non-autoimmune inherited defect in glucose-stimulated insulin secretory mechanism which could result in slow $\beta$-cell destruction and to the formation of antibodies as a secondary event (10). Nonetheless, although the plasma proinsulin response in these subjects was similar to that reported in normoglycaemic first-degree relatives of patients with type 2 diabetes, their insulin secretory capacity differed from that seen in family members of patients affected by type 2 diabetes $(41,42)$, implying that ICA positivity in LADA patients may represent a specific entity. 
We have concluded that the impaired insulin secretory capacity seen in the offspring of LADA patients is characterised by a defect in the processing of proinsulin and could reflect an autoimmune attack on the $\beta$-cell in these subjects. However, heterogeneous plasma proinsulin responses among the offspring of LADA patients suggested that LADA is a heterogeneous disorder likely reflecting differences in $\beta$-cell function among relatives of LADA patients. These findings have provided additional evidence for the heterogeneity of diabetes mellitus, particularly in relation to phenotypes characterised by impaired insulin secretion.

\section{Acknowledgements}

The study was supported by a grant from the Finnish Diabetes Research Foundation. We are indebted to Dr T Tuomi for the collaboration with the analyses of GADAs.

\section{References}

1 Groop LC, Bottazzo GF \& Doniach D. Islet cell antibodies identify latent type 1 diabetes in patients aged 35-75 years at diagnosis. Diabetes $198635237-241$.

2 Irvine WJ, McCallum CJ, Gray RS \& Duncan LJ. Clinical and pathogenic significance of pancreatic-islet-cell antibodies in diabetics treated with oral hypoglycaemic agents. Lancet 1977 i $1025-1027$

3 Niskanen L, Karjalainen J, Sarlund H, Siitonen O \& Uusitupa M. Five-year follow-up of islet cell antibodies in type 2 (non-insulin-dependent) diabetes mellitus. Diabetologia 199134 402-408.

4 Niskanen LK, Tuomi T, Karjalainen J, Groop LC \& Uusitupa MI. GAD antibodies in NIDDM. Ten-year follow-up from the diagnosis. Diabetes Care 199518 1557-1565.

5 Tuomi T, Carlsson A, Li H, Isomaa B, Miettinen A, Nilsson A, Nissen M, Ehrnström BO, Forsen B, Snickars B, Lahti K, Forsblom C, Saloranta C, Taskinen MR \& Groop LC. Clinical and genetic characteristics of type 2 diabetes with and without GAD antibodies. Diabetes $1999 \mathbf{4 8} 150-157$.

6 Turner R, Stratton I, Horton V, Manley S, Zimmet P, Mackay IR, Shattock, Bottazzo GF \& Holman R. UKPDS 25: autoantibodies to islet-cell cytoplasm and glutamic acid decarboxylase for prediction of insulin requirement in type 2 diabetes. UK Prospective Diabetes Study Group. Lancet 1999350 1288-1293.

7 Report of the Expert Committee on the Diagnosis and Classification of Diabetes Mellitus, Diabetes Care 199720 1183-1197.

8 Lohmann T, Kellner K, Verlohren HJ, Krug J, Steindorf J, Scherbaum WA \& Seissler J. Titre and combination of ICA and autoantibodies to glutamic acid decarboxylase discriminate two clinically distinct types of latent autoimmune diabetes in adults (LADA). Diabetologia 200144 1005-1010.

9 Vauhkonen I, Niskanen L, Knip M, Ilonen J, Vanninen E, Kainulainen S, Uusitupa M \& Laakso M. Impaired insulin secretion in non-diabetic offspring of probands with latent autoimmune diabetes mellitus in adults. Diabetologia $20004369-78$.

10 Juneja R \& Palmer JP. Type 1 1/2 diabetes: myth or reality? Autoimmunity $19992965-83$.

11 Snorgaard O, Hartling SG \& Binder C. Proinsulin and C-peptide at onset and during 12 months cyclosporin treatment of type 1 (insulin-dependent) diabetes mellitus. Diabetologia $1990 \quad 33$ $36-42$.

12 Ludvigsson J \& Heding L. Abnormal proinsulin/C-peptide ratio in juvenile diabetes. Acta Diabetologica Latina $198219351-358$.
13 Roder ME, Knip M, Hartling SG, Karjalainen J, Akerblom HK \& Binder C. Disproportionately elevated proinsulin levels precede the onset of insulin-dependent diabetes mellitus in siblings with low first phase insulin responses. The Childhood Diabetes in Finland Study Group. Journal of Clinical Endocrinology and Metabolism 199479 1570-1575.

14 Rodriguez-Villar C, Conget I, Casamitjana R, Vidal J, Manzanares JM \& Gomis R. High proinsulin levels in late pre-IDDM stage. Diabetes Research in Clinical Practice 199737 $145-148$.

15 Spinas GA, Snorgaard O, Hartling SG, Oberholzer M \& Berger W. Elevated proinsulin levels related to islet cell antibodies in firstdegree relatives of IDDM patients. Diabetes Care 199215 $632-637$.

16 Heaton DA, Millward BA, Gray P, Tun Y, Hales CN, Pyke DA \& Leslie RD. Evidence of beta cell dysfunction which does not lead on to diabetes: a study of identical twins of insulin dependent diabetics. British Medical Journal (Clinical Research Edition) 1987 294 145-146.

17 Heaton DA, Millward BA, Gray IP, Tun Y, Hales CN, Pyke DA \& Leslie RD. Increased proinsulin levels as an early indicator of B-cell dysfunction in non-diabetic twins of type 1 (insulin-dependent) diabetic patients. Diabetologia 198831 182-184.

18 Hartling SG, Knip M, Roder ME, Dinesen B, Akerblom HK \& Binder C. Longitudinal study of fasting proinsulin in 148 siblings of patients with insulin-dependent diabetes mellitus. Study Group on Childhood Diabetes in Finland. European Journal of Endocrinology $1997137490-494$.

19 Lindgren FA, Hartling SG, Dahlquist GG, Binder C, Efendic S \& Persson BE. Glucose-induced insulin response is reduced and proinsulin response increased in healthy siblings of type 1 diabetic patients. Diabetic Medicine 19918 638-643.

20 Lindgren FA, Hartling SG, Persson BE, Roder ME, Snellman K, Binder C \& Dahlquist GG. Proinsulin levels in newborn siblings of type 1 (insulin-dependent) diabetic children and their mothers. Diabetologia 199336 560-563.

21 Duckworth WC \& Kitabchi AE. Direct measurement of plasma proinsulin in normal and diabetic subjects. American Journal of Medicine $197253418-427$.

22 Birkeland KI, Torjesen PA, Eriksson J, Vaaler S \& Groop L. Hyperproinsulinemia of type 2 diabetes is not present before the development of hyperglycemia. Diabetes Care $1994 \mathbf{1 7}$ 1307-1310.

23 Porte D Jr. Banting lecture 1990. Beta-cells in type 2 diabetes mellitus. Diabetes 199140 166-180.

24 Niskanen LK, Uusitupa MI, Sarlund H, Siitonen O \& Pyörälä K. Five-year follow-up study on plasma insulin levels in newly diagnosed NIDDM patients and nondiabetic subjects. Diabetes Care $19901341-48$.

25 Uusitupa M, Siitonen O, Aro A \& Pyörälä K. Prevalence of coronary heart disease, left ventricular failure and hypertension in middle-aged, newly diagnosed type 2 (non-insulin-dependent) diabetic subjects. Diabetologia 198528 22-27.

26 World Health Organisation Study Group on Diabetes Mellitus, Technical Report Series No. 727. Geneva: WHO, 1985.

27 DeFronzo RA, Tobin JD \& Andres R. Glucose clamp technique: a method for quantifying insulin secretion and resistance. American Journal of Physiology 1979237 E214-E223.

28 Bowsher RR, Wolny JD \& Frank BH. A rapid and sensitive radioimmunoassay for the measurement of proinsulin in human serum. Diabetes 199241 1084-1090.

29 Haffner SM, Stern MP, Miettinen H, Gingerich R \& Bowsher RR. Higher proinsulin and specific insulin are both associated with a parental history of diabetes in nondiabetic Mexican-American subjects. Diabetes $1995 \mathbf{4 4} 1156-1160$.

30 Karjalainen JK. Islet cell antibodies as predictive markers for IDDM in children with high background incidence of disease. Diabetes $1990391144-1150$. 
31 Rowley MJ, Mackay IR, Chen QY, Knowles WJ \& Zimmet PZ. Antibodies to glutamic acid decarboxylase discriminate major types of diabetes mellitus. Diabetes $1992 \mathbf{4 1} 548-551$.

32 Grubin CE, Daniels T, Toivola B, Landin-Olsson M, Hagopian WA, Li L, Karlsen AE, Boel E, Michelsen B \& Lernmark A. A novel radioligand binding assay to determine diagnostic accuracy of isoform-specific glutamic acid decarboxylase antibodies in childhood IDDM. Diabetologia 199437 344-350.

33 Falorni A, Grubin CE, Takei I, Shimada A, Kasuga A, Maruyama T, Ozawa Y, Kasatani T, Saruta T \& Li L. Radioimmunoassay detects the frequent occurrence of autoantibodies to the Mr 65,000 isoform of glutamic acid decarboxylase in Japanese insulin-dependent diabetes. Autoimmunity $199419113-125$.

34 Vauhkonen IK, Niskanen LK, Mykkänen L, Haffner SM, Uusitupa MI \& Laakso M. Hyperproinsulinaemia is not a characteristic feature in the offspring of patients with different phenotypes of type 2 diabetes. European Journal of Endocrinology $2000143251-260$.

35 Hartling SG, Lindgren F, Dahlqvist G, Persson B \& Binder C. Elevated proinsulin in healthy siblings of IDDM patients independent of HLA identity. Diabetes 198938 1271-1274.

36 Bohmer K, Keilacker H, Kuglin B, Hubinger A, Bertrams J, Gries FA \& Kolb H. Proinsulin autoantibodies are more closely associated with type 1 (insulin-dependent) diabetes mellitus than insulin autoantibodies. Diabetologia 199134 830-834.

37 Bonora E, Zavaroni I, Coscelli C \& Butturini U. Decreased hepatic insulin extraction in subjects with mild glucose intolerance. Metabolism $198332438-446$.
38 Faber OK, Hagen C, Binder C, Markussen J, Naithani VK, Blix PM, Kuzuya H, Horwitz DL, Rubenstein AH \& Rossing N. Kinetics of human connecting peptide in normal and diabetic subjects. Journal of Clinical Investigation 197862 197-203.

39 Zimmet PZ, Tuomi T, Mackay IR, Rowley MJ, Knowles W, Cohen M \& Lang DA. Latent autoimmune diabetes mellitus in adults (LADA): the role of antibodies to glutamic acid decarboxylase in diagnosis and prediction of insulin dependency. Diabetic Medicine $199411299-303$.

40 Gottsater A, Landin-Olsson M, Fernlund P, Lernmark A \& Sundkvist G. Beta-cell function in relation to islet cell antibodies during the first $3 \mathrm{yr}$ after clinical diagnosis of diabetes in type 2 diabetic patients. Diabetes Care $199316902-910$.

41 Eriksson J, Franssila-Kallunki A, Ekstrand A, Saloranta C, Widen E, Schalin C \& Groop L. Early metabolic defects in persons at increased risk for non-insulin-dependent diabetes mellitus. New England Journal of Medicine $1989321337-343$.

42 Vauhkonen I, Niskanen L, Vanninen E, Kainulainen S, Uusitupa M \& Laakso M. Defects in insulin secretion and insulin action in non-insulin-dependent diabetes mellitus are inherited. Metabolic studies on offspring of diabetic probands. Journal of Clinical Investigation $1998 \mathbf{1 0 1} 86-96$.

Received 23 March 2005

Accepted 25 May 2005 